\title{
NIH makes room for the unconventional after Congress mandates new programme
}

Washington. The US National Institutes of Health (NIH) are putting the best possible face on an unwelcome order from Congress to spend $\$ 2$ million a year investigating unconventional medical practices. Insisting that it will maintain the highest scientific standards, NIH has created an office to assess the claims of practitioners of such unorthodox approaches as homeopathy, chelation and ozone therapy.

The order came last autumn in language accompanying the 1992 NIH budget written by the appropriations subcommittee chaired by Senator Thomas Harkin (Democrat, Iowa). It led, two weeks ago, to the first meeting of the ad hoc Advisory Panel on Unconventional Medical Practices, a group of 20 practitioners and supporters representing a broad array of therapies that fall outside the bounds of standard medicine. The group spent two days hearing from advocates of such practices and discussing the evaluation process. A second meeting is planned for the autumn that will focus on issues of methodology.

Even with an annual budget of $\$ 9$ billion, NIH would not have done such a thing on its own, admits Stephen Groft, the director and as yet sole member of the new office. "But money will force you into doing things that you otherwise might not do", he says. A few NIH institutes - notably cancer and infectious diseases - have in the past few years devised a procedure to look at unorthodox treatments, but NIH as a whole has been loath to embrace the idea that it is ignoring potentially life-saving interventions.

Hellen Gelband, who directed a 1990 study by the congressional Office of Technology Assessment (OTA) on unconventional cancer therapies, says that officials from the National Cancer Institute (NCI) treated OTA quite rudely in the course of its inquiry. "They told us they were doing everything that needed to be done, and that we should get out of their way", she recalls. Even before the OTA study was released, however, NCI began a programme that invites practitioners to submit their "best-case series' of results for evaluation.

At the same time, the medical establishment is unhappy that Congress has once again set research priorities for NIH. Representatives of such groups as the American Cancer Society and the American Heart Association admit that some effective treatments were once considered beyond the pale and that it is reasonable to look at the most promising unorthodox approaches to combating cancer, heart disease, AIDS and other potentially fatal diseases. But they dislike the idea that NIH is being told to allocate limited research dollars in ways that might not do the most good.
"Like the poor, unconventional medical practices have always been with us, and there are treatments about which we will never have the answer", says Roy Schwarz, senior vice president for medical education

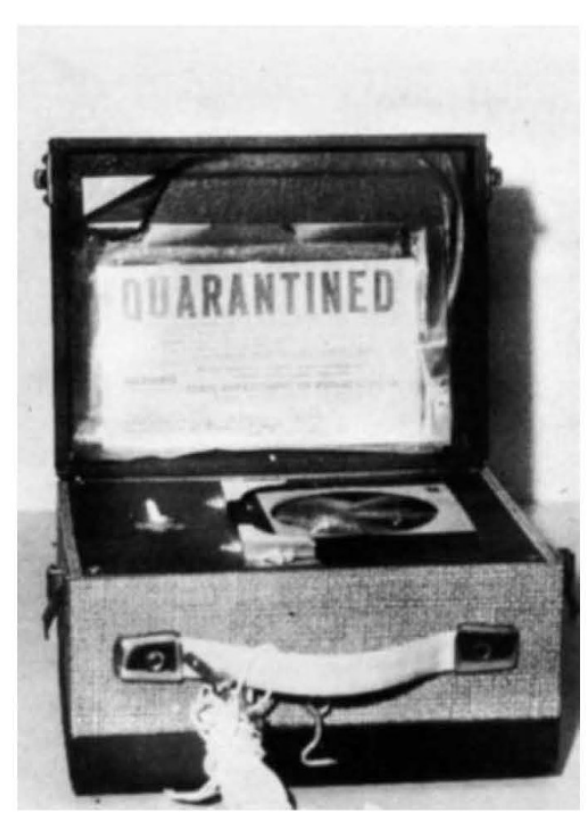

This 'colour therapy' lamp, seized from a California chiropractor in 1966, was said to cure some $\mathbf{3 0}$ conditions ranging from acne to asthma.

and science at the American Medical Association. "Although you hate to dismiss any potentially useful treatment out of hand, there's a lot of good science that isn't getting funded. We would hope that [the new office] consumes no more than a moderate amount of resources."

A congressional aide said that Harkin would like the office to have "half a dozen gumshoes, trained investigators who can go out and examine claims" of unorthodox medical cures and effective treatments. To that end, Groft has requested permission to advertise for three positions, to be filled by experienced researchers holding an MD or $\mathrm{PhD}$ degree and with knowledge of one or more unconventional practices.

For the programme to work, NIH must deal effectively with a group that mistrusts government and that has been a target of the US Food and Drug Administration. "If somebody from a federal agency raided my office, I'd be reluctant to show up on the doorstep of another agency", Groft says. "But our job is to listen to what they have to say."

But it takes two to communicate, and there are those who believe that NIH is wasting its time. "The proponents of these therapies simply will not accept the results if they are negative", says Irving Lerner, a clinical professor of medicine at the University of Minnesota and author of a recent study by the Committee on Questionable Methods of Cancer Management of the American Cancer Society. "Just having the $\mathrm{NIH}$ look at it lends some credence to these questionable therapies."

On the other hand, says Berkley Bedell, a former member of Congress who advised Harkin on the 1992 report language, "the point is to find out what works. And I don't want some researcher to stand in the way of a cure for some dread disease just because it doesn't fit his definition of science."

NIH officials insist that they will not lower their scientific standards in dealing with this unorthodox community. "The more unconventional the approach, the more skeptically it will be viewed" explains Michael Friedman of the division of cancer treatment at NCI. At the same time, the new initiative will require NIH to be more open in judging the merits of a particular approach.

"Just as the zealot relies on his conviction that a particular treatment works, without collecting hard data, the scientific establishment has tended to dismiss these fanatics out of hand, without trying to find ways to obtain the necessary data", says Jack Killen, deputy director of the AIDS division at the National Institute of Allergies and Infectious Diseases. "Sometimes the only difference between unconventional and conventional therapies is the person using them."

Jeffrey Mervis

\section{Panel trims NSF budget}

Washington. The research budget of the National Science Foundation would remain level next year under a measure passed last week by an appropriations subcommittee of the US House of Representatives. The subcommittee ignored NSF's request for an increase of 13 per cent - an additional $\$ 333$ million - and instead gave most of the extra money that it had been allotted to veterans' health care and housing, two other programmes under its jurisdiction. "We're disappointed but not surprised", says one NSF official about the vote. "We knew all along that things were tight, but we were hoping for a little bit more than a flat budget." The next steps, votes by the full committee and House, are not expected much before the end of the month.

Jeffrey Mervis 